\title{
The uptake and fate of Isoniazid in Mycobacterium tuberculosis var. bovis BCG
}

\author{
BY J. W. T. WIMPENNY* \\ Department of Bacteriology, Guy's Hospital Medical School, \\ London, S.E. 1
}

(Accepted for publication 25 January 1967)

SUMMARY

The incorporation of ${ }^{14} \mathrm{C}$ INH into sensitive and resistant bacteria has been investigated. Only organisms susceptible to INH took up the drug. Uptake was irreversible and became saturated at higher INH concentrations. Uptake was heat-labile, KCN-sensitive, partially inhibited by dinitrophenol and stimulated by $\mathrm{SH}$ group reagents. The activation energy of binding was of the same order as the activation energy of an enzyme catalysed reaction. Uptake at $37^{\circ}$ was rapidly inhibited although at $4^{\circ}$ it was not. The INH binding mechanism had many of the properties of catalase and peroxidase. It seems likely that all these functions were part of one enzyme which was missing from INH-resistant BCG.

Chromatographic studies on hot-water extracts of INH-treated BCG indicated that INH was converted into several unidentified products within the organism.

\section{INTRODUCTION}

The effect of isoniazid (INH) on the biosynthesis of a number of components of BCG has been examined in an earlier paper (Wimpenny, 1967). However, in attempting to elucidate both the mode of action and the specificity of INH as an anti-tubercular agent, the fate of the drug itself in the sensitive organism must be traced. Several papers have been published which throw some light on this aspect of the problem. Barclay, Ebert \& Koch-Weser (1953) showed that Mycobacterium tuberculosis var. hominis strain $\mathrm{H} 37 \mathrm{RV}$ sensitive to INH took up the drug, whilst a resistant variant did not. In later experiments (Barclay, Koch-Weser \& Ebert, 1954) using the same organism, they investigated the uptake of ${ }^{14} \mathrm{C}$ isonicotinic acid, ${ }^{14} \mathrm{C}$ nicotinamide and ${ }^{14} \mathrm{C}$ nicotinic acid. Of these compounds, ${ }^{14} \mathrm{C} I N H$ was bound and then only by the drug-sensitive strain. Organisms killed by heat or with formalin did not fix INH. These workers indicated that uptake of INH was greater at $5^{\circ}$ than at $37^{\circ}$ in living bacteria and concluded that INH was bound by physical adsorption. Youatt (1958a) confirmed that ${ }^{14} \mathrm{C}$ INH was bound only by sensitive mycobacteria. She showed that the drug was fixed only under actively metabolizing conditions and that uptake in sensitive mycobacteria was sensitive to cyanide, azide and heat. She found that Staphylococcus aureus, Escherichia coli, Mycobacterium phlei, Proteus mirabilis, Bacillus megatherium and Candida albicans took up very little INH. In addition Youatt showed (1958b) that the rate of breakdown of INH was greater in living BCG than in heat killed organisms.

\footnotetext{
* Present address: Department of Microbiology, University College, Cardiff.
} 
In contrast to the findings of Barclay et al. (1954) referred to above, Youatt found that ${ }^{14} \mathrm{C}$ isonicotinic acid was taken up equally well by sensitive or resistant BCG. She also observed that INH causes the accumulation of a yellow compound in the culture medium from sensitive cells treated with the drug. She tentatively identified this compound as a flavine and suggested that this might reflect a lesion in flavine synthesis.

Boone, Strang \& Rogers (1957), at variance with the findings of Barclay and his co-workers, and with Youatt, have shown that INH-sensitive and INH-resistant Mycobacterium tuberculosis strain $\mathrm{H} 37 \mathrm{RV}$ take up similar quantities of ${ }^{14} \mathrm{C} I N H$. Pyridoxal stimulates uptake of the drug in both strains of organism a hundred-fold.

This work was planned to investigate the uptake and fate of INH in sensitive and resistant bacteria in greater detail.

\section{METHODS}

Organisms and culture. Mycobacterium tuberculosis var. bovis BCG, both INHsensitive and INH-resistant strains, were obtained from Dr J. P. Ungar of Glaxo Laboratories Ltd., Greenford, Middlesex, and were inhibited by 0.1 and by $10 \mu \mathrm{g} . / \mathrm{ml}$. INH respectively. These organisms were maintained and cultured as described by Wimpenny (1967). Escherichia coli NCTC 8164, Staphylococcus aureus strain Oxford NCTC 6571 and Bacillus cereus NRRL 569 were maintained on Dorset egg slopes and subcultured twice in digest broth before use. Corynebacterium xerosis (Guy's Hospital laboratory strain) was stored on blood agar and subcultured twice on digest broth before use.

The last four organisms were resistant to more than $1000 \mu \mathrm{g} . / \mathrm{ml}$. INH. For use these organisms were grown in $100 \mathrm{ml}$. quantities of digest broth in Roux bottles. They were incubated flat at $37^{\circ}$ overnight and used.

Radioactive-tracer techniques. The following ${ }^{14} \mathrm{C}$-labelled compounds were obtained from the Radiochemical Centre, Amersham, Bucks, England: D-glucose ${ }^{14} \mathrm{C}(\mathrm{U})$ $3 \mathrm{mc} / \mathrm{mmole}$; adenine- $8-{ }^{14} \mathrm{C}$ sulphate, $1 \mathrm{mc} / \mathrm{mmole}$; glycine- ${ }^{14} \mathrm{C}(\mathrm{U}), 2 \mathrm{mc} / \mathrm{mmole}$; isonicotinic acid hydrazide (carboxyl ${ }^{14} \mathrm{C}$ ) $2 \mathrm{mc} / \mathrm{mmole}$.

Aqueous solutions of these isotopes were sterilized by autoclaving at 10 p.s.i. for $10 \mathrm{~min}$.

Samples were plated on to $1 \mathrm{~cm}$. nickel planchettes and dried under an infra-red lamp. An end-window Geiger counting tube and Dynatron counting gear were used throughout. All experiments were performed in duplicate.

Incorporation experiments. INH-sensitive and INH-resistant BCG were grown in Aldridge, Felton, Muchmore \& Ramsay (1959), AFMR, medium for 14-21 days. Measured samples of each culture were pipetted aseptically into sterile test-tubes. Each tube also received sterile ${ }^{14} \mathrm{C}$ carbonyl-labelled INH. Other additions of sterile distilled water were used to bring the final volume in each tube to $5.0 \mathrm{ml}$. The final concentration of INH was $0.36 \mu \mathrm{g}$. $/ \mathrm{ml}$, which is equivalent to $0.025 \mu \mathrm{c} / \mathrm{ml}$. isotope. Tubes were incubated as described in each experiment. The cells were then harvested by centrifugation. Cells were washed once in AFMR medium without glucose, then in AFMR medium containing $10 \mathrm{mg} . / \mathrm{ml} .{ }^{12} \mathrm{C}$ INH and finally in glucose-free AFMR medium. Experiments with other organisms were performed in an identical mannerexcept that they were grown in digest broth overnight and they were washed after harvesting at the end of the experiment in normal saline. They were washed again in 
normal saline containing $10 \mathrm{mg} . / \mathrm{ml} .{ }^{12} \mathrm{C} \mathrm{INH}$. The organisms were finally washed in sterile distilled water, before counting.

Chromatography. Concentrated hot-water extracts of cells pretreated with ${ }^{14} \mathrm{C} \mathrm{INH}$ were chromatographed on Whatman no. 1 paper in either $4+1$ isopropanol + water or $5+1+4$ butanol + acetic acid + water. Chromatograms were run overnight, dried and spots detected by ultraviolet photography and radio-autography.

\section{RESULTS}

Fixation of INH by various species of bacteria

The only organism to take up ${ }^{14} \mathrm{C}$ INH to any extent was the INH-sensitive strain of BCG. Resistant BCG took up about $5 \%$ of the quantity fixed by the sensitive cells. The other bacteria took up a negligible amount of INH (Table 1).

Sensitivity to INH appears to be closely related to the ability of the organism to fix the drug.

Table 1. The uptake of labelled INH by different species of bacteria

Duplicate tubes received $0.36 \mu \mathrm{g} .{ }^{14} \mathrm{C} \mathrm{INH} / \mathrm{ml}$. and were incubated for $24 \mathrm{hr}$ at $37^{\circ}$.

Mycobacterium tuberculosis var. bovis BCG

Sensitive to INH

C.p.m./mg. dry cells

Resistant to INH

135

Escherichia coli

Staphylococcus aureus strain OXFORD

Bacillus cereus

Proteus vulgaris

Corynebacterium xerosis

$0 \cdot 8$

1.6

The relationship between concentration of INH and uptake in sensitive and resistant $N C G$

These results have been expressed graphically and, in addition, theoretical curves of INH uptake have been plotted (Fig. 1). These were calculated on the assumption that the ratio of observed to calculated uptake was 1.0 at the maximum concentration tested, and that uptake was directly proportional to the amount of INH available at lower concentrations on all the other points on the graph. Theoretical curves were plotted for both resistant and sensitive organisms, so that a comparison could be made with the observed values.

Resistant organisms show no significant difference between the observed and the theoretical results. In sensitive organisms, however, the uptake of INH was greater at all concentrations lower than the maximum. Moreover, this difference increases as the concentration is decreased. In order to demonstrate this more clearly, the ratios of observed to calculated uptake are plotted in Fig. 2. At concentrations where it could be measured the observed-to-calculated ratio for INH uptake by resistant cells was approximately $1 \cdot 0$. However, this ratio rose to about $4 \cdot 0$ at low INH concentrations in sensitive cells. This demonstrated a qualitative difference in uptake by sensitive and resistant BCG and seemed to indicate that INH was concentrated and fixed in the sensitive cells by an active process. 
INH fixation by sensitive and resistant BCG. Attempts were made to decide whether the mechanism of INH by sensitive cells was an enzymic or a physical process. If INH fixation was reversible in the presence of large amounts of non-radioactive INH, this would lend weight to the adsorption theory. If, however, INH was metabolized by some enzyme, it would no longer be able to exchange with free drug and it would be fixed within the cell.

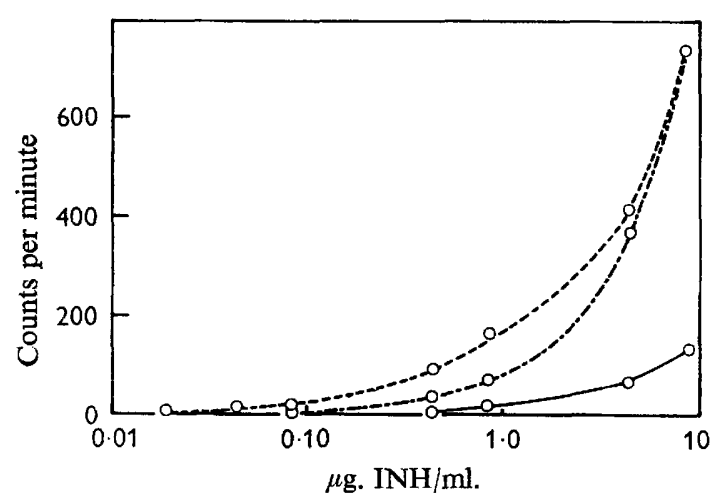

Fig. 1

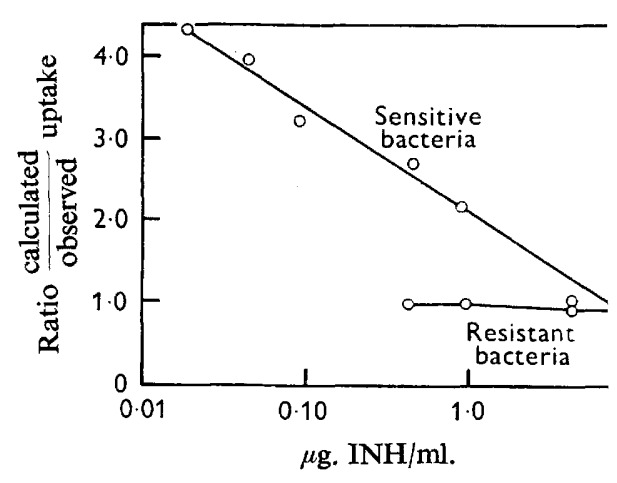

Fig. 2

Fig. 1. The effect of varying ${ }^{14} \mathrm{C} \mathrm{INH}$ concentration on $\mathrm{INH}$ uptake by resistant and sensitive strains of BCG. ...... Observed uptake by sensitive bacteria - . - calculated uptake by sensitive bacteria; - - observed and calculated uptake by resistant bacteria.

Fig. 2. The ratio of observed to calculated INH uptake in INH-sensitive and INH-resistant BCG as a function of ${ }^{14} \mathrm{C}$ INH concentration.

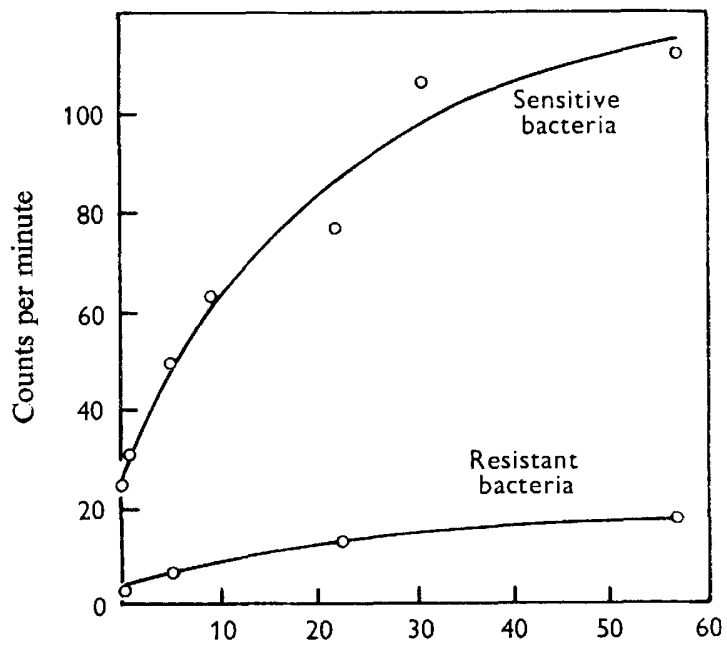

Time in hours at which ${ }^{12} \mathrm{C}$ INH was added

Fig. $3 .{ }^{14} \mathrm{C}$ INH fixation by sensitive and resistant strains of BCG. Cells of each strain were incubated with $0.36 \mu \mathrm{g} . / \mathrm{ml}$. ${ }^{14} \mathrm{C} \Pi \mathrm{NH}$ At various times $100 \mu \mathrm{g} . / \mathrm{ml}$. non-radioactive INH was added. All tubes were incubated for a further $24 \mathrm{hr}$ before the cells were assayed for radioactivity. 
The results of this experiment appear in Fig. 3. It can be seen that INH was rapidly fixed by sensitive cells and was not subsequently released in the presence of high concentrations of non-radioactive isotope. There was only a small increase in irreversibly bound INH in the resistant cells over the same period.

The effect of some conditions, known to influence enzyme reactions, on INH uptake. It seemed desirable to confirm that an enzyme is involved in INH fixation by examining the effect of temperature and several chemical agents, which are known to affect enzyme reactions, on the fixation of INH by sensitive and resistant BCG.

Tubes of 18-day INH-sensitive and INH-resistant BCG cultures were set up as usual. Groups of duplicate tubes of both strains were treated. The results are shown in Table 2.

Table 2. The effect of various conditions on the uptake of ${ }^{14} \mathrm{C} \mathrm{INH}$ by sensitive and resistant strains of $B C G$

Duplicate tubes received $0.36 \mu \mathrm{g} .{ }^{14} \mathrm{C} \mathrm{INH} / \mathrm{ml}$. and were incubated for $40 \mathrm{hr}$ at $37^{\circ}$ except where otherwise stated.

\begin{tabular}{|c|c|c|c|}
\hline Condition & & Counts/min. & Comment \\
\hline Control & $\begin{array}{l}\text { Sensitive } \\
\text { Resistant }\end{array}$ & $\left.\begin{array}{c}135 \\
6.6\end{array}\right\}$ & $\begin{array}{l}\text { Resistant uptake about } 5 \% \text { of } \\
\text { sensitive }\end{array}$ \\
\hline $70^{\circ}$ for $10 \mathrm{~min}$ & $\begin{array}{l}\text { Sensitive } \\
\text { Resistant }\end{array}$ & 26 & $\begin{array}{l}\text { Uptake heat labile, } 80 \% \text { inhibited } \\
\text { Uptake appears to be slightly } \\
\text { stimulated }\end{array}$ \\
\hline $4^{\circ}$ incubation & $\begin{array}{l}\text { Sensitive } \\
\text { Resistant }\end{array}$ & $\begin{array}{l}172 \\
3 \cdot 8\end{array}$ & $\begin{array}{l}\text { Uptake } 28 \% \text { higher than control } \\
\text { No change }\end{array}$ \\
\hline $10^{-2} \mathrm{M}-\mathrm{KCN}$ & $\begin{array}{l}\text { Sensitive } \\
\text { Resistant }\end{array}$ & $\begin{array}{l}7 \cdot 4 \\
9 \cdot 4\end{array}$ & $\begin{array}{l}\text { Uptake completely inhibited } \\
\text { Uptake unaffected }\end{array}$ \\
\hline $10^{-3} \mathrm{M}-\mathrm{PCMB}$ & $\begin{array}{l}\text { Sensitive } \\
\text { Resistant }\end{array}$ & $\begin{array}{r}446 \\
34\end{array}$ & $\begin{array}{l}\text { Uptake } 3 \cdot 3 \text { times the control level } \\
\text { Uptake about } 5 \text { times the control } \\
\text { level }\end{array}$ \\
\hline $4 \times 10^{-4} \mathrm{M}-2,4 \mathrm{DNP}$ & $\begin{array}{l}\text { Sensitive } \\
\text { Resistant }\end{array}$ & $\begin{array}{l}65 \\
7 \cdot 4\end{array}$ & $\begin{array}{l}\text { Uptake about } 50 \% \text { of control } \\
\text { Uptake unaffected }\end{array}$ \\
\hline
\end{tabular}

The control tubes behaved as described in Table 1 in that the resistant cells took up only $5 \%$ of the amount of INH taken up by the sensitive cells.

Exposure to $70^{\circ}$ for $10 \mathrm{~min}$., however, resulted in a drop of $80 \%$ in the uptake of INH by the sensitive cells, whereas the uptake in the resistant cells was slightly increased. Exposure to this temperature for this time commonly inactivates enzyme systems, and this result adds further evidence to the hypothesis that a thermo-labile system is directly involved in INH fixation. In resistant BCG, however, there appeared to be a slight increase in INH uptake, and this could be due to non-specific adsorption of INH on to intracellular constituents, as a result of increased permeability, following destruction of the cytoplasmic membrane.

'Incubation' at $4^{\circ}$ for $40 \mathrm{hr}$ resulted in an increase of about $30 \%$ in uptake of INH by the sensitive cells, whilst the uptake of the resistant cells was not affected.

Parachloromercuribenzoate (PCMB) stimulated the uptake of INH in both sensitive and resistant BCG to about four times the control level.

Potassium cyanide blocked the uptake of INH by sensitive BCG completely, whilst the slight uptake by the resistant cells remained unchanged. 
Cyanide is a common inhibitor of many enzymes, especially those requiring metal cofactors. This suggests once more that INH uptake is mediated by an enzymic process. Again the small amount of INH taken up by resistant cells is unchanged and was similar to the quantity taken up by cyanide-inhibited sensitive cells. This small amount was probably due to contaminating traces of INH adsorbed non-specifically to the cell.

2,4-dinitrophenol inhibited INH uptake in sensitive cells to $50 \%$ of the control level, but uptake by resistant cells remained unchanged. This drug uncouples oxidative phosphorylation which stops production of adenosine triphosphate (ATP) necessary for most energy-requiring reactions. Thus it is possible that an energy-requiring enzyme-catalysed reaction is involved in some aspect of INH uptake.

\section{The effect of temperature on the rate of INH uptake}

Sensitive BCG grown for 21 days on AFMR medium were incubated at $4^{\circ}, 25^{\circ}$ and $37^{\circ}$, in duplicate, for various times from 0 to $24 \mathrm{hr}$ with ${ }^{14} \mathrm{C} \mathrm{INH}$. Uptake was followed over the first $24 \mathrm{hr}$ and these results are shown in Fig. 4. It can be seen that the rate of INH uptake varied at the three temperatures tested. During the first $2 \mathrm{hr}$ INH was fixed most rapidly at $37^{\circ}$ and $25^{\circ}$. However, this fixation fell off quickly and by the $24 \mathrm{th}$ hr the order of total uptake at the three temperatures was reversed, the greatest amount of INH being fixed at $4^{\circ}$ and the least at $37^{\circ}$.

This experiment was repeated over the narrower range from 0 to $2 \mathrm{hr}$, as it appeared that INH was fixed more rapidly at $37^{\circ}$ than at either of the other temperatures tested during the first $2 \mathrm{hr}$. The results obtained are shown in Fig. 5.

It can be seen that the initial rate of uptake was lowest at the lower temperatures. The initial rates of INH uptake were measured at the three different temperatures and the $\log$ of this reaction velocity (expressed as $\log _{10}$ counts $/ 5 \mathrm{~min} . / \mathrm{hr}$ ) has been plotted against the reciprocal of the absolute temperature (Fig. 6). The slope of this graph can be used to determine the approximate activation energy of the reaction. This has been done four times and the mean figure for $E$ appears to be $9900 \mathrm{cal} / \mathrm{mole}$ with a standard deviation of $2100 \mathrm{cal} . / \mathrm{mole}$, which is of the order of magnitude of the activation energy of a typical enzyme catalysed reaction. This distinguishes it from the very low or negative activation energies of physical adsorption.

Incubation at $37^{\circ}$ and its effect on INH uptake at $4^{\circ}$. The fact that prolonged 'incubation' at $4^{\circ}$ causes a greater uptake of INH than incubation at $37^{\circ}$ for a similar period prompted the question: can organisms exposed to INH at $37^{\circ}$ for various times subsequently take up more INH when incubated at $4^{\circ}$ than organisms incubated at $4^{\circ}$ all the time? Cultures were therefore incubated for various times from 0 to $20 \mathrm{hr}$ at $37^{\circ}$ with ${ }^{14} \mathrm{C} \mathrm{INH}$, and then stored for $24 \mathrm{hr}$ at $4^{\circ}$. The results of this experiment appear in Fig. 7. It can be seen that, when the organisms were incubated at $37^{\circ}$ and then held at $4^{\circ}$, they took up proportionately less INH the longer they were pre-incubated at $37^{\circ}$. Organisms held at $4^{\circ}$ throughout the period of the experiment took up most INH of all.

The heat lability of the uptake system

Cultures of INH-sensitive and INH-resistant BCG were exposed to $60^{\circ}$ for various times between 0 and $20 \mathrm{~min}$. and tested for INH uptake by adding ${ }^{14} \mathrm{C}$ INH and incubating for $24 \mathrm{hr}$. INH uptake in sensitive organisms fell rapidly as the length of 


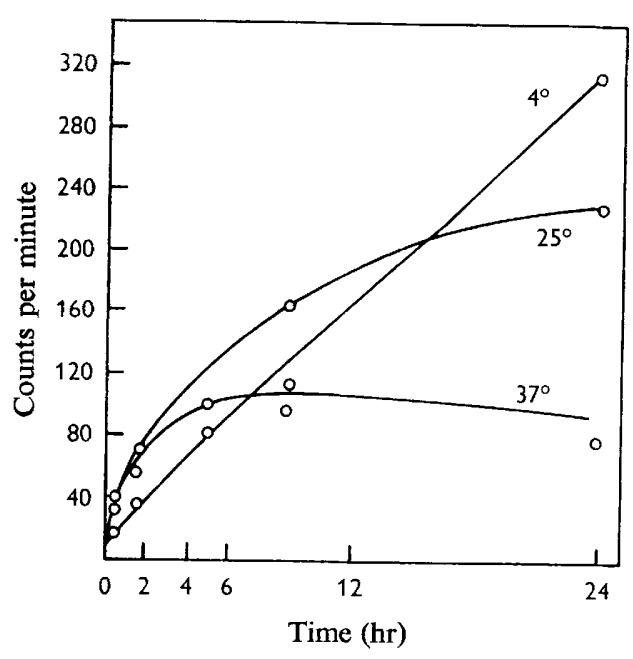

Fig. 4

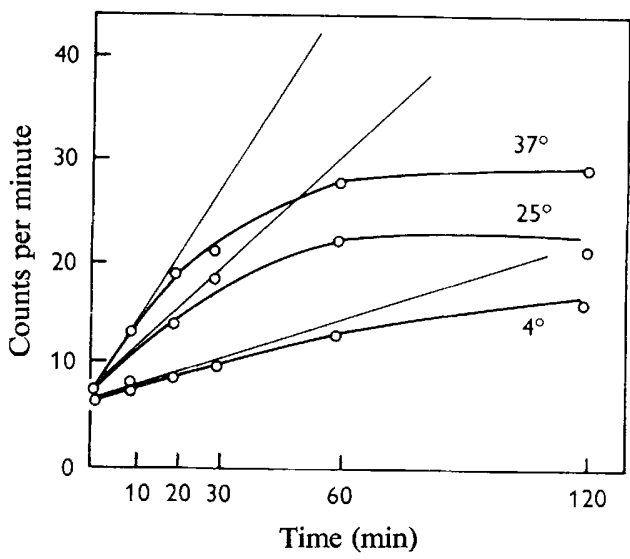

Fig. 5

Fig. 4. ${ }^{14} \mathrm{C}$ IHN uptake as a function of time, at $4^{\circ}, 25^{\circ}$ and $37^{\circ}$ by INH-sensitive BCG. Each tube received $0.36 \mu \mathrm{g} . / \mathrm{ml} .{ }^{14} \mathrm{C}$ INH. At each sampling time $500 \mu \mathrm{g} .{ }^{12} \mathrm{C}$ INH was added to each tube.

Fig. 5. Uptake of ${ }^{14} \mathrm{C} \mathrm{INH}$ at $4^{\circ}, 25^{\circ}$ and $37^{\circ}$ in INH-sensitive BCG, over the first 2 hr of incubation with the drug. Each tube received $0.36 \mu \mathrm{g} . / \mathrm{ml} .{ }^{14} \mathrm{C} \mathrm{INH}$. At each sampling time $500 \mu \mathrm{g} .{ }^{12} \mathrm{C}$ INH was added to each tube.

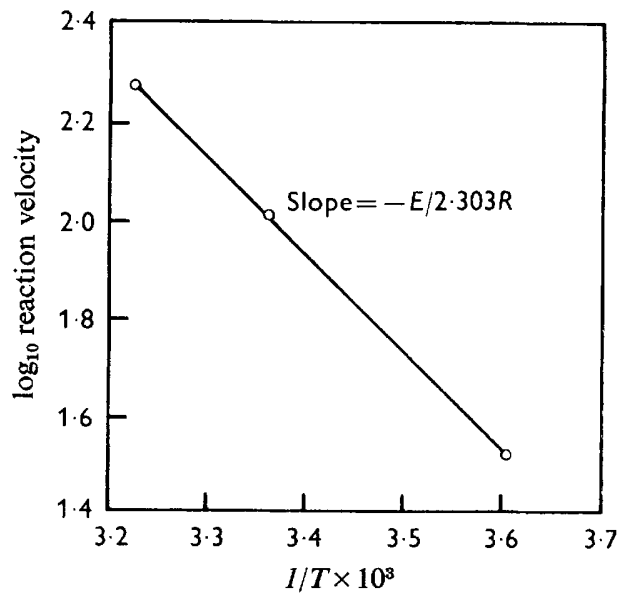

Fig. 6

Fig. 6. The $\log$ of the initial rate of ${ }^{14} \mathrm{C}$ INH uptake, determined from Fig. 5, plotted against the reciprocal of the absolute temperature.

exposure increased (Fig. 8). After about $10 \mathrm{~min}$. at $60^{\circ}$ the uptake by sensitive and resistant bacteria was about the same, and probably represents non-specific adsorption on to the same cellular component. However, about $80 \%$ of the total INH uptake of sensitive bacteria was heat-labile as this was blocked after $10 \mathrm{~min}$. exposure to $60^{\circ}$.

The effect of parachloromercuribenzoate $(P C M B)$ on the incorporation of INH into tubercle bacilli. During the preliminary survey of the effects of various conditions on 


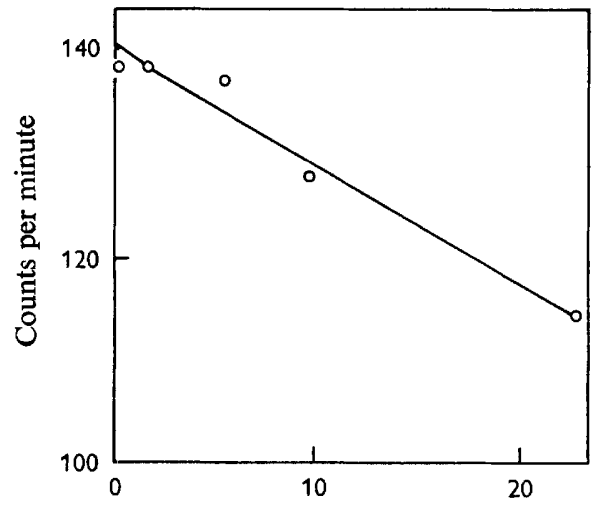

Hours of preincubation at $37^{\circ}$

Fig. 7

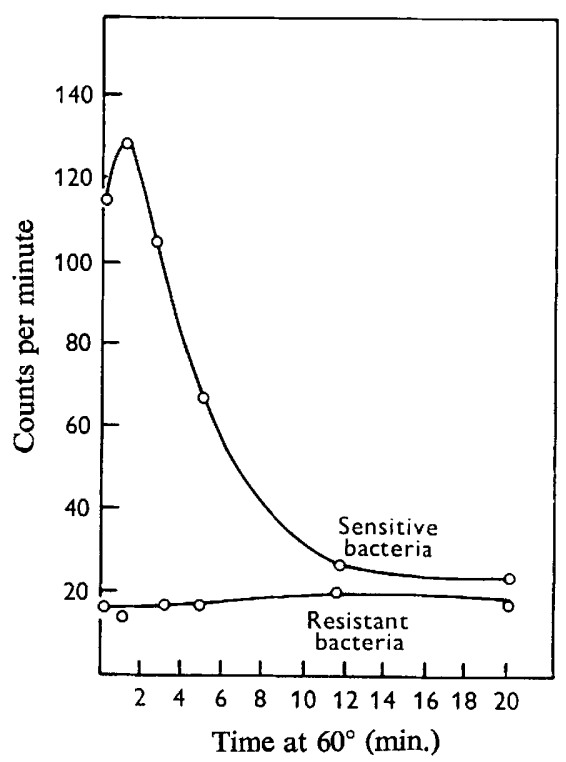

Fig. 8

Fig. 7. Incubation of INH-sensitive BCG with ${ }^{14} \mathrm{C} \mathrm{INH}$ at $37^{\circ}$ and its effect on INH uptake at $4^{\circ}$. Each tube received $0.36 \mu \mathrm{g} . / \mathrm{ml} .{ }^{14} \mathrm{C} \mathrm{INH}$, and was incubated for various times at $37^{\circ}$, before being stored at $4^{\circ}$ for $24 \mathrm{hr}$.

Fig. 8. The effect of exposure to $60^{\circ}$ for various times on ${ }^{14} \mathrm{C}$ INH uptake in INH-resistant and INH-sensitive strains of BCG. Tubes were maintained at $60^{\circ}$ in a water bath for various times, before being incubated for $24 \mathrm{hr}$ at $37^{\circ}$ with $0 \cdot 36 \mu \mathrm{g} . / \mathrm{ml} .{ }^{14} \mathrm{C} \mathrm{INH}$. Cells were subsequently assayed for radioactivity.

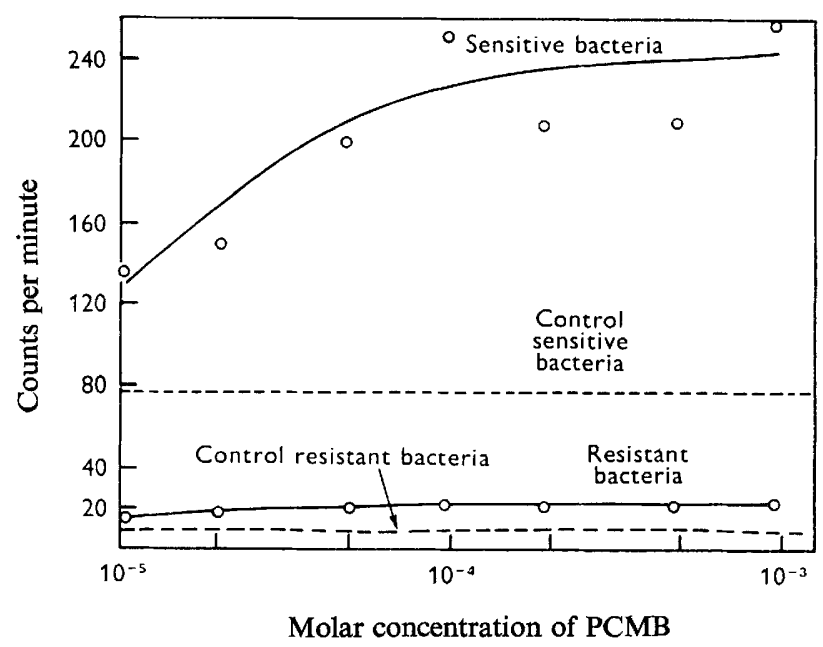

Fig. 9. The effect of various concentrations of PCMB on ${ }^{14} \mathrm{C} \mathrm{INH}$ uptake by INH-sensitive and INH-resistant strains of BCG. Each tube received 0.36 $\mu \mathrm{g} . /{ }^{14} \mathrm{C} \mathrm{INH}$ and various concentrations of PCMB. After incubating at $37^{\circ}$ for $40 \mathrm{hr}$ the cells were assayed for radioactivity in the usual way. 
the incorporation of INH into BCG it was shown that $10^{-3} \mathrm{M}-\mathrm{PCMB}$ stimulated INH uptake 3-4 times.

It was decided to compare the uptake of INH in INH-sensitive and INH-resistant BCG, treated with concentrations of PCMB between $10^{-5}$ and $10^{-3} \mathrm{M}$. These results (Fig. 9) show that with both sensitive and resistant strains INH uptake was stimulated by all concentrations of PCMB tested. The INH uptake that was observed in resistant cells, although small, was increased about twofold.

The effect of heat on INH uptake stimulated by $P C M B$. The effect of heat on ${ }^{14} \mathrm{C}$ INH uptake in sensitive BCG treated with PCMB was examined. The results (Fig. 10) show that the increased uptake due to PCMB treatment was as labile as the control uptake.

Table 3. The effect of $10^{-3} \mathrm{M}-\mathrm{PCMB}$ on the uptake of normal metabolites by INH-sensitive and INH-resistant BCG

\begin{tabular}{|c|c|c|c|c|}
\hline Compound & BCG & $\begin{array}{l}10^{-3} \mathrm{M}- \\
\text { PCMB }\end{array}$ & Counts/min. & $\begin{array}{l}\text { Percentage } \\
\text { of control }\end{array}$ \\
\hline \multirow[t]{2}{*}{$2 \mu \mathrm{c}$ adenine } & Sensitive & $\overline{+}$ & $\left.\begin{array}{l}348 \\
121\end{array}\right\}$ & $35 \%$ \\
\hline & Resistant & $\overline{+}$ & $\left.\begin{array}{r}689 \\
52\end{array}\right\}$ & $7 \cdot 5 \%$ \\
\hline \multirow[t]{2}{*}{$5 \mu \mathrm{C}$ glycine } & Sensitive & $\bar{t}$ & $\left.\begin{array}{r}20,040 \\
67\end{array}\right\}$ & $0 \cdot 3 \%$ \\
\hline & Resistant & $\overline{+}$ & $\left.\begin{array}{r}21,111 \\
194\end{array}\right\}$ & $0.9 \%$ \\
\hline \multirow[t]{2}{*}{$1 \mu \mathrm{C}$ glucose } & Sensitive & $\overline{+}$ & $\left.\begin{array}{c}108 \\
18\end{array}\right\}$ & $17 \%$ \\
\hline & Resistant & - & $\left.\begin{array}{r}163 \\
25\end{array}\right\}$ & $15 \%$ \\
\hline
\end{tabular}

The effect of PCMB on the uptake of normal metabolites by INH-sensitive and INHresistant $B C G$. The influence of $\mathrm{PCMB}$ on the uptake of three normal metabolites was examined; these were adenine, glycine and glucose. The results are presented in Table 3. It can be seen that in every case $10^{-3} \mathrm{M}-\mathrm{PCMB}$ inhibited the uptake of these substances. The effect was particularly noticeable with ${ }^{14} \mathrm{C}$ glycine.

PCMB interfered either with the uptake or the metabolism of three normal metabolites of INH-sensitive and INH-resistant $\mathrm{BCG}$, in contrast to its effect on INH uptake.

The effect of other sulphyldryl (SH) group inhibitors on INH uptake. Two compounds were chosen: $N$-ethylmaleimide and iodoacetic acid.

The results are shown in Table 4 and from these it can be seen that both iodoacetic acid and $N$-ethylmaleimide stimulated INH uptake in both sensitive and resistant BCG. The increased uptake in sensitive bacteria was not as great as the stimulation observed with PCMB. However, the effect of both agents on INH uptake in resistant organisms was very marked.

The heat-lability of INH uptake in INH-sensitive or INH-resistant BCG treated with $\mathrm{N}$-ethlymaleimide or iodoacetic acid. Stimulation of INH uptake by $\mathrm{N}$-ethylmaleimide and iodoacetic acid was studied further by measuring the effect of heat on the system. With resistant BCG (Fig. 11) the enhanced INH uptake due to these reagents was 
increased even further by heat treatment. However, with sensitive BCG (Fig. 12), although $N$-ethylmaleimide stimulated the uptake of $\mathrm{INH}$, this uptake was also heatlabile. Examination of the latter part of the curve shows that uptake with or without the drug rose as the time of exposure to $60^{\circ}$ increased, although uptake in the presence of $N$-ethylmaleimide was always higher. Comparison of this graph with Fig. 11 showing the heat lability of INH uptake in resistant organisms exposed to these drugs indicates that the shape of the latter part of the curve after $5 \mathrm{~min}$. exposure to $60^{\circ}$ is similar in both cases. It is probable that INH uptake follows a similar course in both strains of BCG except that a heat-labile mechanism binding INH exists in the sensitive organisms whilst this is not present in the resistant bacteria.

Table 4. The effect of $\mathrm{N}$-ethylmaleimide and iodoacetic acid on the uptake of isoniazid by sensitive and resistant BCG bacilli

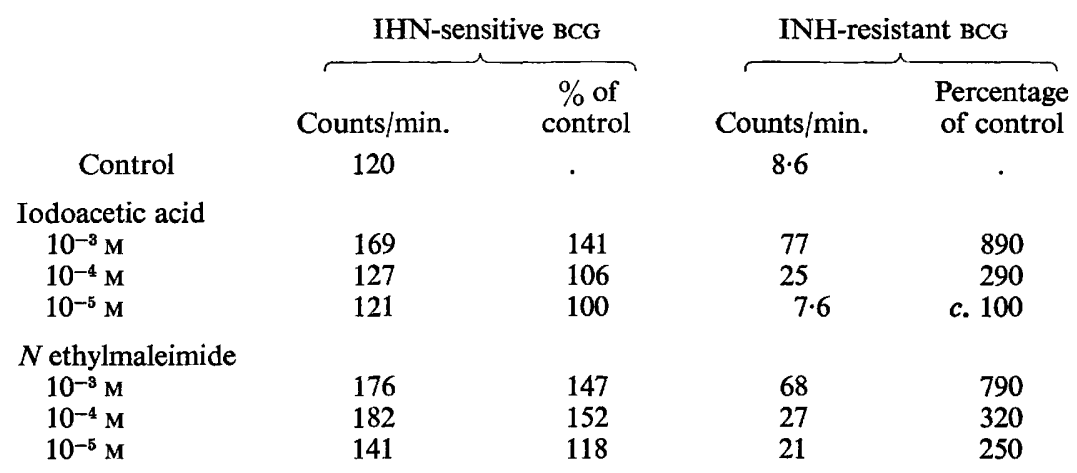

The effect of PCMB, $\mathrm{N}$-ethylmaleimide and iodoacetic acid on INH uptake in three species of bacteria. Three organisms were chosen: Escherichia coli, Staphylococcus aureus and Bacillus cereus. Cultures of each organism were treated with one of the three reagents or distilled water, and ${ }^{14} \mathrm{C} \mathrm{INH}$. Only negligible quantities of INH were taken up by each of the three organisms.

The extraction and chromatography of ${ }^{14} \mathrm{C} I N H$ and its metabolites from $\mathrm{INH}$ sensitive $B C G$. It seems likely that INH is converted by INH-sensitive BCG to some metabolite and this compound is responsible for the toxic effect of the drug in the bacterium. However, at present the nature of this substance is unknown.

It was decided to attempt the extraction of the radioactive INH and its derivatives bound by INH-sensitive BCG and to analyse this extract chromatographically.

Chromatographic examination of the hot-water extract of sensitive BCG treated with ${ }^{14} \mathrm{C}$ INH for $42 \mathrm{hr}$ showed that less than $5 \%$ of the activity could be accounted for as INH or any of three breakdown products-isonicotinic acid, isonicotinamide or diisonicotinylhydrazine. Most of this activity remained at the origin in both solvent systems (see Methods). It seems clear from this experiment that the fate of INH in INH-sensitive BCG was more complex than had hitherto been thought likely. It is obvious that a detailed chemical analysis of the metabolism of INH by tubercle bacilli is necessary and that this will throw more light on the mode of action of the drug. 


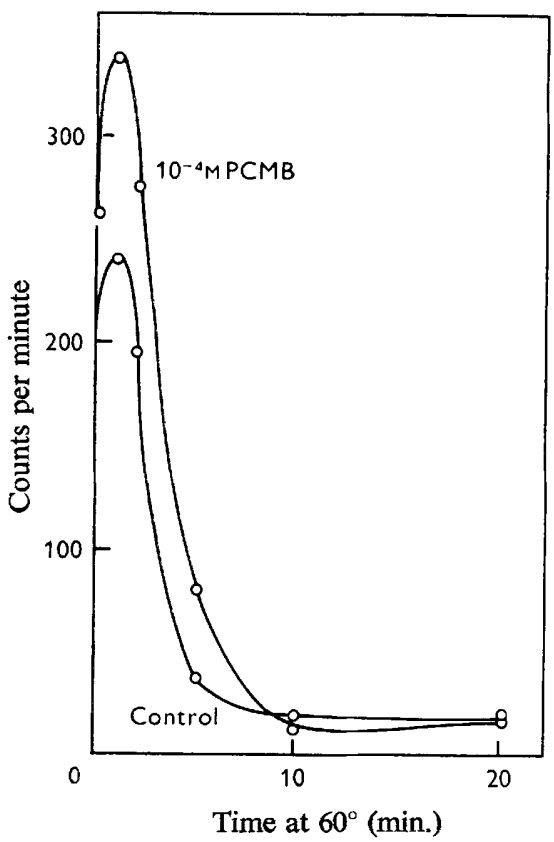

Fig. 10

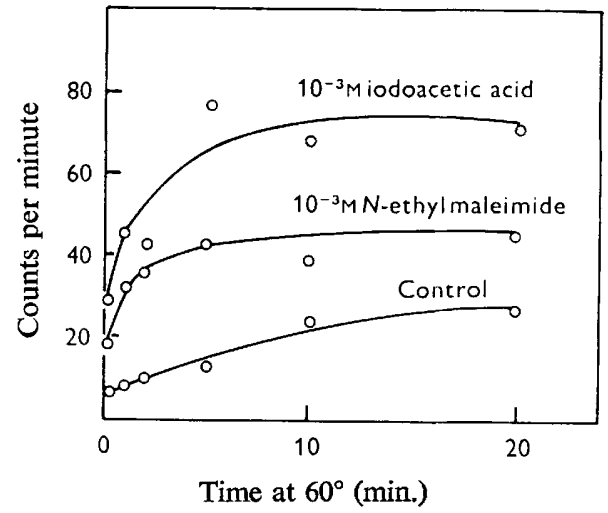

Fig. 11

Fig. 10. Exposure to $60^{\circ}$ for various times on ${ }^{14} \mathrm{C}$ INH uptake in INH sensitive BCG, in the presence and absence of PCMB. Experimental details as for Fig. 8.

Fig. 11. The effect of heat on ${ }^{14} \mathrm{C} I N H$ uptake in INH-resistant BCG treated with $N$-ethylmaleimide or iodoacetic acid. Experimental details as for Fig. 8.

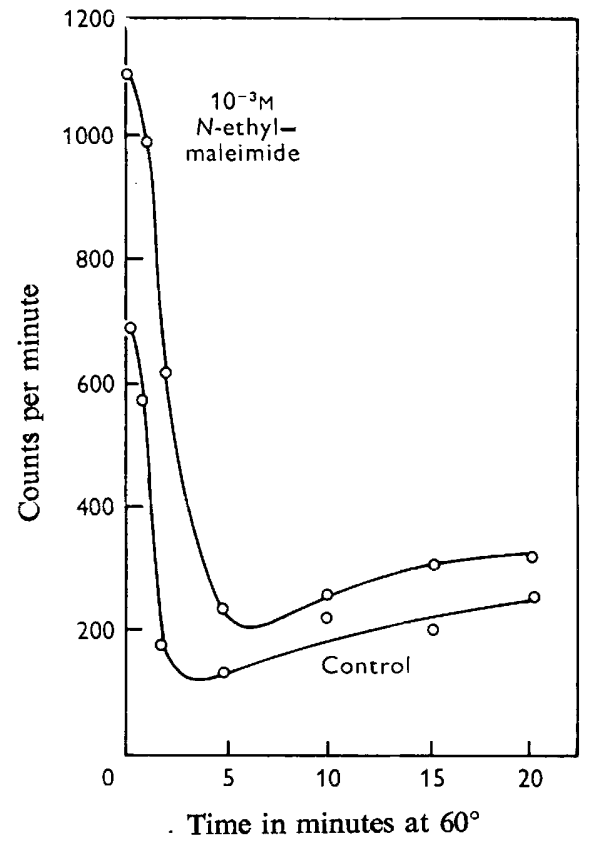

Fig. 12. The heat-lability of ${ }^{14} \mathrm{C}$ INH uptake in INH-sensitive BCG treated with $\mathrm{N}$-ethylmaleimide. Experimental details as for Fig. 8. 


\section{DISCUSSION}

The bulk of the evidence presented in this paper indicates the enzymic nature of INH uptake. This evidence will be discussed and a working hypothesis for INH action will be examined.

The relationship between the sensitivity of mycobacteria to INH and the mode of action of the drug requires accurate knowledge of the process by which the drug arrives at its site of action within the cell.

Early experiments were designed to correlate sensitivity to INH with uptake of the drug. These experiments showed that only sensitive organisms could take up INH. INH-resistant mycobacteria take up considerably less INH. Organisms normally naturally resistant fixed least INH of all. Whatever the mechanism of INH uptake therefore, the drug is found only in organisms which are sensitive to it. Uptake kinetics are qualitatively different when sensitive and resistant organisms are exposed to different concentrations of ${ }^{14} \mathrm{C} \mathrm{INH}$. Whilst the small uptake in resistant organisms is directly proportional to concentration, the high uptake in sensitive organisms becomes progressively saturated as the drug concentration rises. It seems likely that if INH was bound to the cell by non-specific physical adsorption the subsequent addition of high concentrations of non-radioactive INH would drastically reduce the amount of bound INH. In practice the binding of INH at $37^{\circ}$ is irreversible. The sensitivity of INH uptake to different agents was examined. Uptake is sensitive to cyanide and partially sensitive to 2,4-dinitrophenol. Cyanide inhibits many enzyme systems, including those containing haem prosthetic groups.

2,4-dinitrophenol is a powerful uncoupler of oxidative phosphorylation and it is possible that INH uptake requires energy. This point has not been investigated further. In contrast to the effects of cyanide and 2,4-dinitrophenol, sulphydryl group reagents such as $p$-chloromercuribenzoate, $N$-ethylmaleimide or iodoacetic acid all stimulate INH uptake. This observation is clearest with PCMB. However, with all these reagents the additional uptake in sensitive cells is heat-labile though not in resistant organisms. Several explanations for this observation are possible. (i) SH-group reagents may nonspecifically either assist in the binding of INH to the cell or alternatively increase the permeability of the cell to INH. The fact that uptake in sensitive though not resistant bacteria is heat-labile points to a greater degree of specificity than this explanation would imply. (ii) SH group reagents might inhibit a mechanism which metabolizes INH once it enters the cell and which under normal conditions itself limits the amount of INH that the sensitive cell can absorb. This latter is the preferred explanation in view of later experiments on INH uptake as a function of temperature. Earliest experiments showed, in agreement with Barclay and his co-workers, that incubation at low temperatures results in increased INH uptake. This was examined most carefully when INH uptake was measured as a function of time at these different temperatures. It was clear from these results that the initial rate of INH uptake was fastest at the higher temperatures. However, this rate rapidly falls off and at later times the picture is reversed and more INH appears in cells incubated in the cold. When the initial rate of INH uptake is expressed as a classical Arrhenius plot the energy of activation of the uptake process can be roughly estimated. In these experiments a figure of about $10,000 \mathrm{cal}$./mole is obtained which is of the order of magnitude of activation energy of an enzyme catalysed reaction. In common with the effect of SH-group reagents a higher INH uptake 
is observed under the least physiologically suitable condition, in this case at $4^{\circ}$. It seems therefore that at $37^{\circ}$ one component of the INH binding system is active and becomes rapidly and irreversibly saturated. This does not occur in the presence of SHgroup reagents or at $4^{\circ}$. Careful examination of the sensitivity to heat of the INH uptake system by exposing cells to temperatures of $60^{\circ}$ for various times shows uptake by sensitive cells to be quite labile. Uptake is reduced to the level in resistant cells after $10 \mathrm{~min}$.

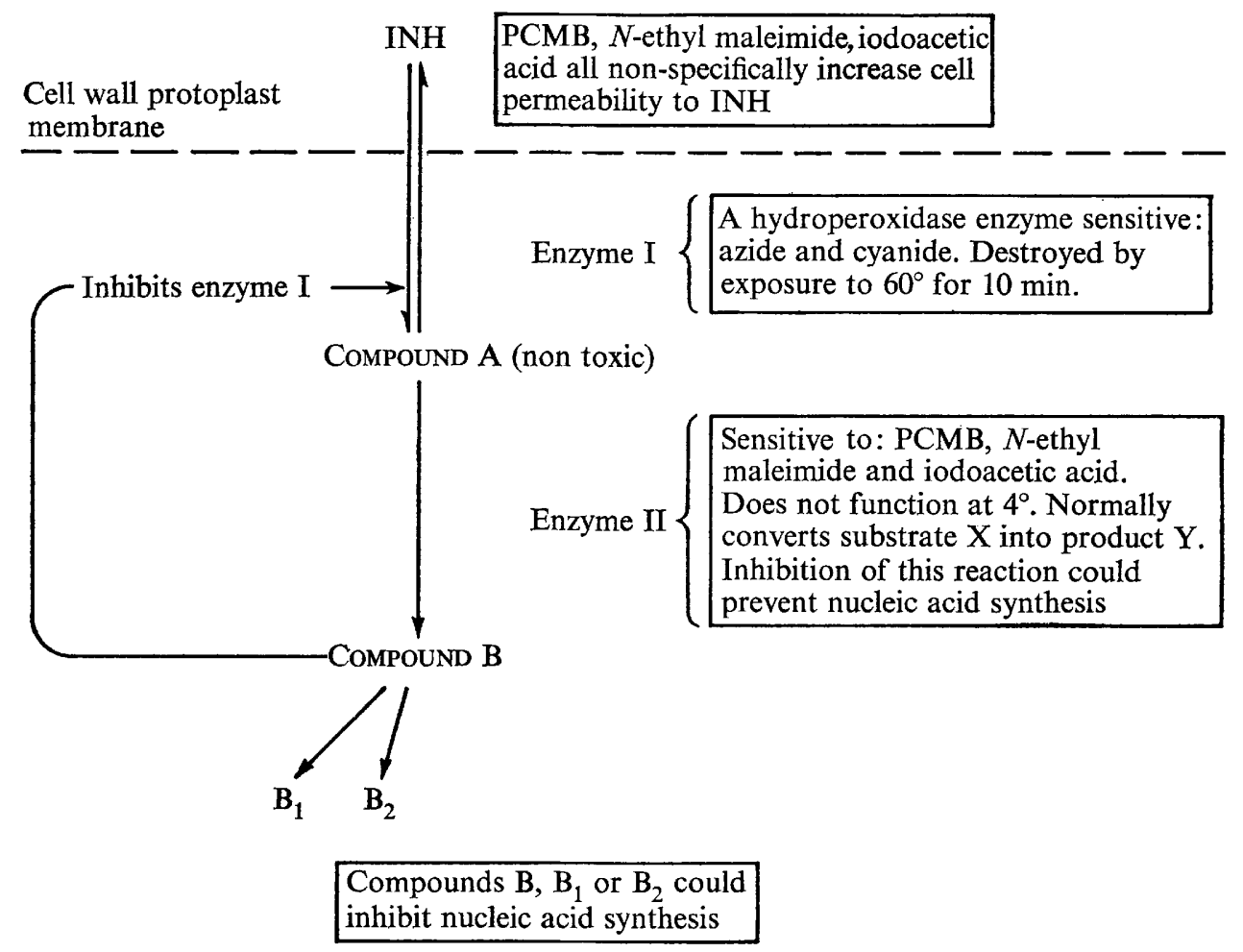

Fig. 13. A hypothetical scheme for the mode of action of INH.

Examination of all the available evidence leads to the conclusion that INH is bound in sensitive mycobacteria by a heat-labile protein molecule and that INH uptake has the activation energy of an enzymatic process.

On the basis of evidence derived from this paper and from other workers a tentative model for INH uptake is proposed (Fig. 13).

INH is taken up by sensitive mycobacteria at the active centre of enzyme I. Enzyme I is probably the hydroperoxidase enzyme which has been shown to be missing in resistant strains of mycobacteria (Middlebrook, Cohn \& Schaeffer, 1954; Tirunarayanan \& Vischer 1959). This enzyme is heat-labile, sensitive to cyanide and also to azide (Youatt, $1958 b$ ).

INH reacts to form compound A which can be a metabolite of INH or free INH, and this is then released into the cell. Compound $A$ is not in its own right toxic and is reversibly bound by the bacteria. At $37^{\circ}$ compound $\mathrm{A}$ is converted into compound $\mathrm{B}$ by a second enzyme, enzyme II. The product of this reaction inhibits the uptake of 
INH by enzyme I and compound B or another metabolite of compound B is toxic to the bacteria by interfering with nucleic acid synthesis (Wimpenny, 1967). The reaction catalysed by enzyme II is not reversible, does not take place at $4^{\circ}$ and is probably inhibited by the SH group reagents PCMB, iodoacetic acid and $N$-ethylmaleimide. Enzyme $I$ is not affected by any of these agents, and hence compound A accumulates to a greater extent in these than in control INH-treated cells. It is probable that the SH-group reagents also increase cell permeability to INH non-specifically in both INH-sensitive and INH-resistant BCG, as well as inhibiting the reaction of enzyme II. It may be that INH partially inhibits enzyme I although there is little evidence to confirm this. $80-90 \%$ of the isotope can subsequently be extracted with hot water when INH-sensitive bacteria are incubated with ${ }^{14} \mathrm{C}$ INH. Chromatographic techniques show that a number of compounds other than INH or any of its normal breakdown products (isonicotinic acid, diisonicotinyl hydrazine or isonicotinamide) contain radioactivity. The most active of these remains stationary at the origin in two solvent systems. These unidentified compounds may be products of enzyme I or II or of subsequent reactions of these products. Resistant cells have lost enzyme I and hence cannot fix INH. However, as enzyme I has properties of catalase and peroxidase these organisms are now sensitive to $\mathrm{H}_{2} \mathrm{O}_{2}$. In these cells, even in the presence of INH, there is no compound A to serve as a substrate for enzyme II and the cells grow normally.

It is difficult to fit the results described in this paper and those presented by other workers into any simpler theoretical framework. The fact that the enzyme responsible for INH uptake in sensitive cells appears to be missing in resistant organisms makes it unlikely that this enzyme is one whose normal function in tubercle bacilli is necessary to the reproduction and growth of the cell. It follows that a second step must occur, the result of which is an inhibition of nucleic synthesis. But INH uptake at $37^{\circ}$ appears to become rapidly saturated. Therefore, a metabolite of INH must inhibit the enzyme responsible in the first place for the uptake of the drug. This metabolite or another product of INH metabolism exercises its effect on nucleic acid synthesis. The formation of compound A (whether this is free INH or not) also explains the fact that INH is taken up to a greater extent at low temperatures and that this compound is reversibly bound to the cell (Barclay et al. 1954) because under these conditions the reaction catalysed by enzyme II cannot take place as compound B which normally inhibits INH uptake is not formed.

This report is prepared in part from a thesis presented to the University of London 1962, for the degree of Doctor of Philosophy. The author is grateful to Professor R. Knox for his constant help and encouragement, and to the Endowment Fund of Guy's Hospital for a research grant. 


\section{REFERENCES}

Aldridge, C., Felton, F. G., Muchmore, H. G. \& Ramsay, H. H. (1959). A new liquid synthetic medium for the cultivation of Mycobacterium species. Am. Rev. resp. Dis. 80, 267.

Barclay, W. R., Ebert, R. H. \& Koch-Weser, D. (1953). Mode of action of isoniazid. Am. Rev. Tuberc. 67, 490.

Barclay, W. R., Koch-Weser, D. \& Ebert, R. H. (1954). Mode of action of isoniazid. III. Am. Rev. Tuberc. 70, 784.

Boone, I. U., Strang, V. G. \& Rogers, B. S. (1957). Effect of pyridoxal on uptake of ${ }^{14}$ C-activity from labelled isoniazid by Mycobacterium tuberculosis. Am. Rev. Tuberc. 76, 568.

Middlebrook, G., Cohn, M. L. \& SchaEfFer, W. B. (1954). Studies on isoniazid and tubercle bacilli. III. Am. Rev. Tuberc. 70, 852 .

Tirunarayanan, M. O. \& VISCher, W. A. (1959). Inactivation of isoniazid by peroxidase. Nature, Lond. 183, 681 .

WIMPENNY, J. W. T. (1967). Effect of isoniazid on biosynthesis in Mycobacterium tuberculosis var. bovis BCG. J. gen. Microbiol. 47, 379.

YouATt, J. (1958a). The uptake of isoniazid by washed cell suspensions of Mycobacteria and other organisms. Aust. J. exp. Biol. med. Sci. 36, 223.

YouATT, J. $(1958 b)$. Metabolism of isoniazid by Mycobacterium tuberculosis BCG with reference to current theories of the mode of action. Am. Rev. Tuberc. 78, 806. 